\title{
An investigation of the neural correlates of attention and effector switching using ERPs
}

\author{
Robert West, Kira BaILey, ANd Moses M. LANGLey \\ Iowa State University, Ames, Iowa
}

\begin{abstract}
Event-related brain potentials (ERPs) were used to examine the neural correlates of attention and effector switching when one or both types of switches were performed on a given trial. The response time data revealed that switch costs tended to increase from attention switches to effector switches to attention+effector switches. For right-hand responses, attention switching was associated with a parietal slow wave and effector switching was associated with a central readiness potential. For left-hand responses, attention switching was associated with a parietal slow wave, and effector switching was associated with a parietal slow wave and a readiness potential. These data suggest that the independence of the neural systems supporting attention and effector switching may be limited to instances where the dominant hemisphere controls the response.
\end{abstract}

The ability to rapidly shift from one task to another on the basis of changing environmental demands has been taken as a hallmark of efficient executive or cognitive control (Allport, Styles, \& Hsieh, 1994; Logan, 2003; Miller \& Cohen, 2001; Monsell, 2003). Following the seminal publication of Rogers and Monsell (1995), there has been intense interest in the cognitive processes and neural architecture supporting task switching. In studies using behavioral methods, various investigators have demonstrated that task switching is supported by distinct cognitive processes associated with cue retrieval (Logan \& Bundesen, 2003), task set configuration (Monsell \& Mizon, 2006), advanced preparation (Altmann, 2004), and rule mapping (Mayr \& Kliegl, 2003). In studies incorporating neuromonitoring methods, investigators have begun to identify the temporal dynamics of distinct areas within the frontal and parietal cortices that support different cognitive processes related to task switching (Braver, Reynolds, \& Donaldson, 2003; Dove, Pollmann, Schubert, Wiggins, \& von Cramon, 2000; Rushworth, Passingham, \& Nobre, 2002; Yeung, Nystrom, Aronson, \& Cohen, 2006). The present study used eventrelated brain potentials (ERPs) to examine the neural correlates of attention switching, where the relevant stimulus attribute changed from one trial to the next, and effector switching, where the relevant effector (e.g., response hand) changed from one trial to the next, and to consider the locus of competition that may arise when two switches must be performed on a given trial. This study extends previous research that has largely, although not exclusively (see Kleinsorge \& Heuer, 1999; Tieges, Snel, Kok, Plat, $\&$ Ridderinkhof, 2007), focused on the performance of a single type of task switch within a given investigation.

Studies using functional magnetic resonance imaging (fMRI) and focal lesion methods have made significant progress in characterizing the functional neuroanatomy supporting task switching. Evidence from studies using fMRI consistently demonstrates that task switching is associated with the recruitment of a neural network that includes lateral and medial prefrontal cortex, supplementary motor area, parietal cortex, and subcortical structures involved in motor control and attentional allocation-for example, basal ganglia and thalamus (Braver et al., 2003; Dove et al., 2000; Smith, Taylor, Brammer, \& Rubia, 2004; Yeung et al., 2006). The role of cortical and subcortical structures in task switching has been confirmed in studies of patients with focal lesions. Damage to the prefrontal cortex or basal ganglia can result in magnified switch costs reflected by elevated error rates and increased response time (RT) when task switching is required (Aron et al., 2003; Mayr, Diedrichsen, Ivry, \& Keele, 2006; Ravizza \& Ciranni, 2002; Woodward, Bub, \& Hunter, 2002). Additionally, evidence from studies using transcranial magnetic stimulation demonstrates that transient activation of lateral and medial prefrontal cortex can lead to reductions in switch costs (Rushworth, Hadland, Paus, \& Sipila, 2002; Vanderhasselt, De Raedt, Baeken, Leyman, \& D'haenen, 2006).

The findings of studies incorporating ERPs generally converge with the functional neuroimaging literature in revealing modulations of the ERPs (P2, P3a, P3b, parietal slow wave) that are distributed over the frontal and parietal regions of the scalp and are associated with different processes supporting task switching (Kieffaber \& Hetrick, 2005; Nicholson, Karayanidis, Bumak, Poboka, \& Michie, 2006; Poulsen, Luu, Davey, \& Tucker, 2005; Rushworth, Passingham, \& Nobre, 2002, 2005). Over the frontal region of the scalp, the P2 and P3a components may be greater in amplitude for trials in mixed blocks than for 
trials in pure blocks, leading to the suggestion that these components are associated with cue encoding (Kieffaber \& Hetrick, 2005). Over the parietal region of the scalp, the $\mathrm{P} 3 \mathrm{~b}$ is greater in amplitude for trials in mixed blocks than for trials in pure blocks (Kieffaber \& Hetrick, 2005; Kray, Eppinger, \& Mecklinger, 2005; West, 2004). The P3b may (Jost, Mayr, \& Rösler, 2008; Kieffaber \& Hetrick, 2005; Tieges et al., 2007) or may not (Eppinger, Kray, Mecklinger, \& John, 2007; Travers \& West, 2008; West \& Moore, 2005) vary in amplitude for different types of trials within mixed blocks. Together these findings indicate that the P3b may reflect processes associated with both cue encoding and task switching (Jost et al., 2008). Following the P3b, the parietal slow wave distinguishes cue switches and task switches from repetitions within mixed blocks of trials (Jost et al., 2008; Nicholson et al., 2006), and may be modulated by differences in the processing demands of the two tasks (Travers \& West, 2008). These findings reveal that the parietal slow wave is likely associated with processes supporting both cue retrieval and task set configuration. Furthermore, when transparent task cues (i.e., cues in which there is a preexisting association between the cues and tasks; Logan \& Bundesen, 2003; Mayr \& Kliegl, 2003) are used, the parietal slow wave seems to primarily reflect processes associated with task set configuration (Travers \& West, 2008; West \& Travers, 2008).

The neural correlates of attention, effector, and attention + effector switching were compared in one recent study (Tieges et al., 2007). In this experiment, participants were asked to report whether a stimulus was red or blue, or whether it was a consonant or a vowel, by pressing a set of keys with the index and middle fingers of the right and left hands. An attention switch represented a change in the relevant stimulus dimension from one trial to the next; an effector switch represented a change in the relevant fingers from one trial to the next; and an attention+effector switch represented a change in the relevant stimulus dimension and response fingers from one trial to the next. The RT data revealed that switch costs were greater for attention switches than for effector switches, and that the costs of performing a dual switch $(M=120 \mathrm{msec})$ were roughly additive relative to the single switch costs (effector $M=38 \mathrm{msec}+$ attention $M=95 \mathrm{msec}=133 \mathrm{msec})$. The authors also found that the amplitude of the P3b (and parietal slow wave) was greater for switches than for repetitions in all three conditions and that this effect was greater for dual switches than for attention switches. These findings may indicate that similar processes support cue retrieval and task set configuration during attention and effector switching. Additionally, the increase in the amplitude of the P3b and parietal slow wave from attention switches to attention + effector switches may indicate that those processes indexed by the P $3 \mathrm{~b}$ and parietal slow wave are sensitive to the complexity of the switch that is required on a given trial.

The present study was designed to examine three questions motivated by the work of Tieges et al. (2007). First, we sought to determine whether there might be differential effects of attention and effector switching on the P3b and parietal slow wave. In analyzing their ERP data, Tieges et al. did not distinguish between the effects of task switching on the P3b and parietal slow wave; however, these modulations of the ERPs have been differentially associated with processes related to cue encoding, cue retrieval, and task set configuration in some recent studies (Jost et al., 2008; Nicholson et al., 2006; West \& Travers, 2008). Second, we sought to implement an alternative manipulation of effector switching that might better distinguish between the ERP correlates of attention and effector switching. To this end, we had individuals switch between response hands rather than between fingers for the effector switch. Finally, we sought to examine the effect of attention and effector switching on the P3b and parietal slow wave in a paradigm using transparent task cues rather than nontransparent cues (i.e., cues in which the relationship between the cues and tasks represents a novel association) that were used by Tieges et al. Some evidence indicates that nontransparent cues may lead to the recruitment of processes associated with cue retrieval that influence the amplitude of the P3b and parietal slow wave (Travers \& West, 2008). Given this, we wondered whether the influence of cue retrieval resulting from the use of nontransparent cues might have obscured differences between attention and effector switching related to task set configuration that are manifest in the parietal slow wave (Travers \& West, 2008).

To address these issues, individuals performed a task where they identified the color or identity of an incongruent Stroop color word (Stroop, 1935) from a cue presented before stimulus onset. The cues represented the letters $(\mathrm{C}$ or $\mathrm{W})$ presented to the left or right of fixation (e.g., a $\mathrm{C}$ to the left of fixation indicated that the participant should identify the color of the stimulus using the left hand; Figure 1). The use of Stroop stimuli provides one means of teasing apart the influence of cue encoding or retrieval and task set configuration on the $\mathrm{P} 3 \mathrm{~b}$ and parietal slow wave. Prior research indicates that the parietal slow wave, but not the P3b, is greater in amplitude for the color task than for the word task over the left parietal region of the scalp, which likely reflects differences in the ease of task set configuration between the two tasks (Travers \& West, 2008; West \& Moore, 2005). Four types of trials were included in the design. For repetitions, the relevant stimulus dimension and response hand were maintained across consecutive trials. For attention switches, the relevant stimulus dimension changed from one trial to the next and the relevant response hand remained the same. For effector switches, the response hand changed from one trial to the next and the relevant stimulus dimension remained the same. Finally, for attention+effector switches, the relevant stimulus dimension and response hand changed from one trial to the next.

Several predictions related to the questions under examination were considered. If similar processes contributed to task set configuration for attention and effector switching, we expected the P3b and parietal slow wave to be greater in amplitude between 400 and $1,000 \mathrm{msec}$ after cue onset for the three types of switches relative to repetitions. If attention and effector switching both required access to a common process associated with task set configuration, we expected the amplitude of the $\mathrm{P} 3 \mathrm{~b}$ 

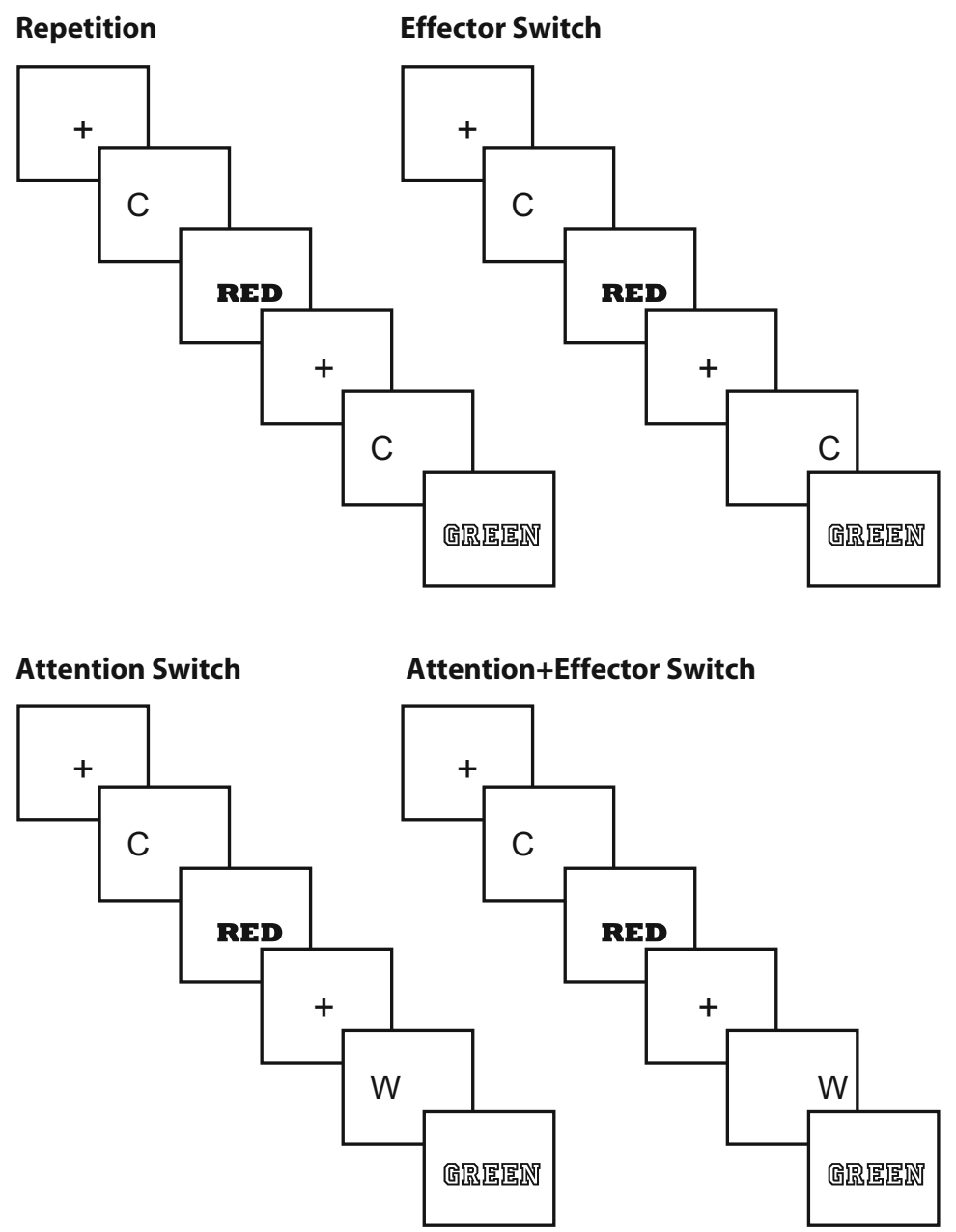

Figure 1. Examples of the stimulus sequence for repetitions, effector switches, attention switches, and attention + effector switches. The stimuli were RED presented in green or GREEN presented in red.

and parietal slow wave to be greater for attention + effector switches than for attention or effector switches. If early frontal recruitment is associated with cue encoding (Kieffaber \& Hetrick, 2005), we expected that the amplitude of the anterior P2 or P3a would be greater for switch trials than for repetitions. Finally, we expected that effector switches would elicit a readiness potential over the central region of the scalp that would be contralateral to the response hand (Coles, Smid, Scheffers, \& Otten, 1995). To evaluate these predictions, we examine the ERPs during the cue-to-stimulus interval when configuration of the task set would be expected (Jost et al., 2008; Travers \& West, 2008).

\section{METHOD}

\section{Participants}

Thirty-two individuals ( 17 males and 15 females; $M=19.75$ years, $S D=1.67$ ) participated in the study. Data for 4 participants were excluded because of their responses to the Edinburgh handedness inventory (Oldfield, 1971): 1 was clearly left-handed and 3 had intermediate negative scores, or scores near 0 , indicating no general hand preference. Data for 2 other individuals were excluded from the analyses, given excessive levels of artifact in the EEG data. Individuals were recruited from an online participant pool maintained by the psychology department, and were undergraduates registered in first- and second-year introductory and survey courses. Participants provided informed consent at the beginning of the testing session and received course credit for participation in the study that was approved by the human participant institutional review board of the university.

\section{Materials}

The task cues were the uppercase letters $\mathrm{C}$ or $\mathrm{W}$ and the target stimuli were incongruent Stroop color words (i.e., RED in green or GREEN in red). For the $\mathrm{C}$ cue, individuals were to identify the color of the stimuli, and for the $\mathrm{W}$ cue, individuals were to identify the word represented by the target stimuli. For all trials, red was mapped to the left ("V" key) and right ("N" key) index fingers and green was mapped to the left ("C" key) and right ("M" key) middle fingers. In the key-mapping phase, the stimuli were strings of four Xs that were presented in either red or green. All stimuli were presented on a black background in uppercase bold Arial 14-point font and were vertically and horizontally centered in the display. The task was programmed using the E-Prime 1.2 software (Psychology Software Tools, Pittsburgh, PA). 


\section{Design}

The task switching paradigm included three phases (key mapping, practice, and test). In the key-mapping phase, participants learned the color-to-key mappings used in the practice and test phases. Participants began by practicing the left-hand responses for 40 trials ( 20 red and 20 green), then practiced the right-hand responses for 40 trials. The order of stimulus presentation in the key-mapping phase was random. In the practice phase, individuals completed one block of 24 trials that each included five displays. First, a fixation cross was presented for $1,000 \mathrm{msec}$ to orient attention to the center of the display; then, a task cue was presented $1.4^{\circ}$ to the left or right of fixation for $250 \mathrm{msec}$, followed by a blank screen for $750 \mathrm{msec}$. When the cue was presented to the left of fixation, individuals were to respond with the left hand, and with the right when the cue was presented to the right of fixation. Following this, the target stimulus was presented in the center of the display until the response. The final display provided feedback indicating whether the response was correct or incorrect. The feedback was presented for $1,000 \mathrm{msec}$, then the fixation cross for the next trial was presented. For the practice trials, 12 trials required a word response and 12 a color response; 12 trials required a left-hand response, and 12 a right-hand response. In the test phase, individuals completed five blocks of 192 trials that represented 12 repetitions of the 16 task conditions within each block. The 16 task conditions represented a 2 (dimension: color or word) $\times 2$ (response hand: left or right) $\times$ 4 (type of switch: repetitions, attention switches, effector switches, attention+effector switches) factorial design. For repetitions, the task cue and response hand was the same on consecutive trials; for attention switches, the task cue changed from one trial to the next and was on the same side of the display across trials. For effector switches, the cue remained the same from one trial to the next and the location of the cue changed from one side of the display to the other; for attention +effector switches, the location and identity of the task cue changed from one trial to the next. To ensure that equal numbers of each trial type appeared within each block, the trials within a block were presented in a fixed quasi-random order for all participants. The sequence of displays for the test blocks was identical to the practice block, with the exception that feedback regarding the accuracy of the response was not provided.

\section{Procedure}

Upon arriving at the laboratory, participants were given a verbal description of the study and written informed consent was obtained. Individuals then completed the Edinburgh handedness inventory (Oldfield, 1971), were fitted with an Electro-cap, then moved to an electrically shielded room where the task switching paradigm was performed. Following completion of the task, the Electro-cap was removed, individuals were allowed to wash their hair and were then debriefed as to the purpose of the study.

\section{Electrophysiological Recording and Analysis}

The electroencephalogram (EEG, bandpass .02-150 Hz, digitized at $500 \mathrm{~Hz}$, gain 1,000, 16-bit A/D conversion) was recorded from an array of 68 tin electrodes sewn into an Electro-cap or affixed to the skin with an adhesive patch that was interfaced to a DBPA-1 (Sensorium Inc., Charlotte, VT). Vertical and horizontal eye movements were recorded from four electrodes placed below or beside the eyes. During recording, all electrodes were referenced to electrode $\mathrm{Cz}$. For data analysis, the electrodes were referenced to an average reference (Picton et al., 2000). Considerable alpha activity was observed in the cue-to-stimulus interval for a number of the participants, so a .1- to 8-Hz zero-phase-shift bandpass filter was applied to the EEG data before averaging. Ocular artifacts associated with blinks were corrected using the EMSE software (Source Signal Imaging, San Diego). Trials contaminated by other artifacts (peak-to-peak deflections greater than $100 \mu \mathrm{V}$ ) were rejected before averaging. ERP epochs included data for correct responses where RT was less than 5,000 msec. The ERP epoch included -200 to $1,000 \mathrm{msec}$ of activity around the onset of the task cues.
Differences in peak or mean ERP amplitude between the three types of task switches were considered in a set of ANOVAs using the Huynh-Feldt (Huynh \& Feldt, 1976) corrected degrees of freedom when necessary. The amplitude of the P3b was quantified as peak voltage at electrode Pz 300-500 msec after cue onset. The amplitude for the frontal-central negativity was quantified as mean voltage at electrode $\mathrm{FCz} 400-500 \mathrm{msec}$ after cue onset. The amplitude of the readiness potential was quantified as mean voltage at electrodes FC3-FC4, C3-C4, and C5-C6 between 300 and 1,000 msec after cue onset. The amplitude of the parietal slow wave was quantified as mean voltage at electrodes $\mathrm{P} 3, \mathrm{Pz}$, and $\mathrm{P} 4$ 600-1,000 msec after cue onset. The amplitude of the frontal slow wave was quantified as mean voltage at electrodes F7, F5, F6, and F8 600-1,000 msec after cue onset. For all but the frontal-central negativity and frontal slow wave, these electrode locations and epochs were selected on the basis of the results of prior studies examining the ERP correlates of task switching (Jost et al., 2008; Kieffaber \& Hetrick, 2005; Travers \& West, 2008) or the readiness potential (Coles et al., 1995). Since the frontal negativity - and, to some degree, the frontal slow wave-reflect novel findings, the electrodes selected for the analyses of these modulations of the ERPs represented the locations where the effects appeared to be maximal in amplitude. A measure of peak amplitude was used to quantify the P3 in the hope of distinguishing it with the trailing parietal slow wave, and measures of mean amplitude were used to quantify the other modulations of the ERPs (i.e., frontal negativity, parietal slow wave, frontal slow wave, readiness potential) that did not have a clear peak.

As a complement to the analyses of mean amplitude, we also present the scalp voltage and surface Laplacian maps for four of the modulations of the ERPs (frontal-central negativity, readiness potential, parietal slow wave, frontal slow wave) that were examined in the analyses. The surface Laplacian maps provide an estimate of the current distribution at the cortical surface that is blurred in the scalp voltage maps because of volume conduction and tangential flow of current across the scalp (Nunez \& Srinivasan, 2006; Srinivasan, 2005). The surface Laplacian maps can be particularly informative when we visualize the distribution of activity attributable to two or more relatively local current sources or sinks that may appear as a single broadly distributed area of activity in the scalp voltage maps (Nunez \& Srinivasan, 2006).

\section{RESULTS}

\section{Behavioral Data}

The response accuracy and RT data are presented in Table 1. In analyzing these data, we first calculated the costs (switch trial minus repetition) associated with the

Table 1

Means and Standard Deviations for Response Accuracy (Proportion Correct) and Response Time (in Milliseconds) for Repetitions, Attention Switches, Effector Switches, and Attention + Effector Switches

\begin{tabular}{|c|c|c|c|c|c|c|c|c|}
\hline & \multicolumn{4}{|c|}{ Response Accuracy } & \multicolumn{4}{|c|}{ Response Time } \\
\hline & \multicolumn{2}{|c|}{$\begin{array}{l}\text { Right } \\
\text { Hand }\end{array}$} & \multicolumn{2}{|c|}{$\begin{array}{l}\text { Left } \\
\text { Hand }\end{array}$} & \multicolumn{2}{|c|}{$\begin{array}{l}\text { Right } \\
\text { Hand }\end{array}$} & \multicolumn{2}{|c|}{$\begin{array}{l}\text { Left } \\
\text { Hand }\end{array}$} \\
\hline & $M$ & $S D$ & $M$ & $S D$ & $M$ & $S D$ & $M$ & $S D$ \\
\hline Color Repetitions & .94 & .07 & .93 & .09 & 797 & 220 & 832 & 235 \\
\hline Attention & .89 & .08 & .88 & .08 & 862 & 200 & 918 & 233 \\
\hline Effector & .90 & .09 & .88 & .10 & 916 & 218 & 942 & 252 \\
\hline Attention +effector & .87 & .10 & .85 & .11 & 1,004 & 266 & 957 & 200 \\
\hline Word Repetitions & .95 & .05 & .95 & .07 & 739 & 200 & 785 & 222 \\
\hline Attention & .94 & .07 & .92 & .07 & 838 & 241 & 824 & 218 \\
\hline Effector & .92 & .09 & .92 & .08 & 879 & 236 & 857 & 227 \\
\hline Attention + effector & .90 & .09 & .91 & .07 & 952 & 281 & 991 & 308 \\
\hline
\end{tabular}


Left-Hand Responses

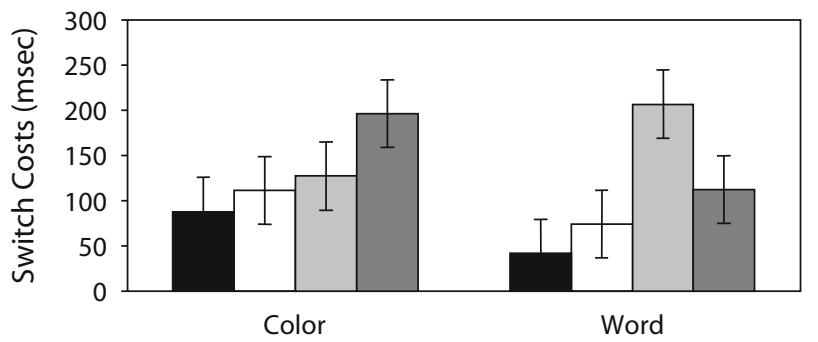

Right-Hand Responses

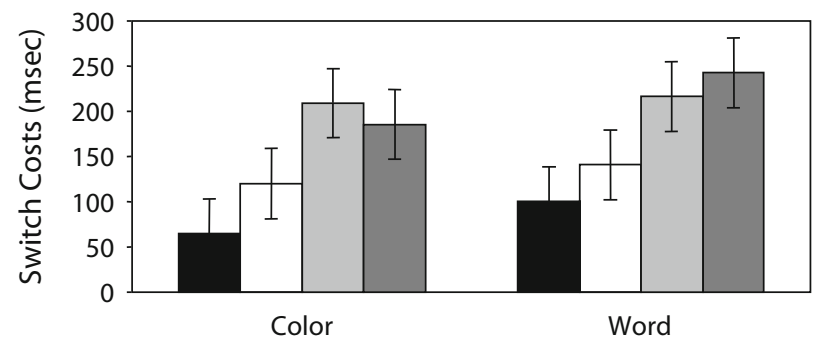

Attention+effector $\square$ Combined

Figure 2. Switch costs for response time (switch type - repetition trial) for attention, effector, and attention + effector switches, and the "combined" switch costs (attention + effector = combined) for comparison. The error bars represent the $95 \%$ confidence interval based on the error term for the three-way interaction. The error bars for the combined switch costs are solely for illustrative purposes and did not contribute to the calculation.

three types of task switches (attention, effector, and attention+effector) for accuracy and RT.

A 2 (dimension) $\times 2$ (response hand) $\times 3$ (type of switch) ANOVA performed on the switch costs for the response accuracy data revealed a significant effect of type of switch $\left[F(2,50)=7.24, p<.002, \eta_{\mathrm{p}}^{2}=.23\right]$. The effect of type of switch reflected similar switch costs for attention switches $(M=.04)$ and effector switches $(M=.04$, $F<1.00$ ); and greater switch costs for attention+effector switches $(M=.06)$ than when a single switch was required $\left[F(1,25)=15.59, p<.01, \eta_{\mathrm{p}}^{2}=.38\right] .{ }^{1}$ These data indicate that the costs associated with having to perform the two types of switches on the same trial were greater than those associated with having to performing either of the types of switches on a given trial.

A similar ANOVA performed on the RT costs revealed a main effect of the type of switch $[F(2,50)=33.10, p<$ $\left..001, \eta_{\mathrm{p}}^{2}=.59\right]$ and a dimension $\times$ response hand $\times$ type of switch interaction $\left[F(2,50)=4.55, p<.02, \eta_{\mathrm{p}}^{2}=.15\right]$. As can be seen in Figure 2, the three-way interaction resulted from differences in the degree that switch costs were independent or interactive across the type of switches. For the right hand, the main effect of type of switch was significant $\left[F(2,50)=19.74, p<.001, \eta_{\mathrm{p}}^{2}=.44\right]$ and reflected increasing costs from attention switches to effector switches $\left[F(1,25)=5.98, p<.02, \eta_{\mathrm{p}}^{2}=.19\right]$ and from effector switches to attention+effector switches $[F(1,25)=19.38$, $\left.p<.001, \eta_{\mathrm{p}}^{2}=.44\right]$. An additional analysis where switch costs for attention and effector switches were pooled (attention switch costs + effector switch costs) and compared with switch costs for attention + effector switches revealed that the two types of costs were additive $(F<1.00)$. For the left hand, the dimension $\times$ type of switch interaction was significant $\left[F(2,50)=6.57, p<.003, \eta_{\mathrm{p}}^{2}=.21\right]$. For the color task, the magnitude of the various switch costs was not significantly different across the types of switches $\left[F(2,50)=1.23, p>.30, \eta_{\mathrm{p}}^{2}=.05\right]$; and for the word task the switch costs were different $[F(2,50)=19.95, p<$ $\left..001, \eta_{\mathrm{p}}^{2}=.44\right]$, being similar for attention switches and effector switches $\left[F(1,25)=2.82, p>.11, \eta_{\mathrm{p}}^{2}=.11\right]$, and greater for attention + effector switches than for effector switches $\left[F(1,25)=13.62, p<.001, \eta_{\mathrm{p}}^{2}=.35\right]$, and for attention + effector switches than for attention switches
$\left[F(1,25)=43.26, p<.001, \eta_{\mathrm{p}}^{2}=.63\right]$. Additionally, there was a trend for attention + effector switch costs to be subadditive in the color task $\left[F(1,25)=3.20, p<.09, \eta_{\mathrm{p}}^{2}=\right.$ $.11]$ and to be superadditive in the word task $[F(1,25)=$ $\left.6.14, p<.02, \eta_{\mathrm{p}}^{2}=.20\right]$. The results of these analyses reveal that the attention +effector switch costs may be subadditive, additive, or superadditive, depending on the response hand and the task performed. Specifically, for right-hand responses, attention and effector switches appear to be additive; in contrast, for left-hand responses, switching to the color dimension may be done in parallel, whereas switching to the word dimension may result in competition between the two types of switches.

\section{ERP Data}

Task switching appeared to have little effect on the amplitude of the P3b (Figure 3). To verify this, a 4 (type of switch $) \times 2$ (dimension) $\times 2$ (response hand) ANOVA was performed on peak amplitude between 300 and $500 \mathrm{msec}$ after cue onset at electrode $\mathrm{Pz}$. In this analysis, the main effect of trial was not significant $[F(3,75)=1.25, p>.30$, $\left.\eta_{\mathrm{p}}^{2}=.05, \varepsilon=.98\right]$, revealing only small differences in the amplitude of the $\mathrm{P} 3 \mathrm{~b}$ across the four task conditions (repetitions, $M=3.89 \mu \mathrm{V}$; effector switches, $M=4.01 \mu \mathrm{V}$; attention switches, $M=3.98 \mu \mathrm{V}$; and attention+effector switches, $M=4.17 \mu \mathrm{V})$. In addition, none of the interactions involving the variable type of switch were significant $\left(F_{\mathrm{s}}<2.05, p>.11, \eta_{\mathrm{p}}^{2}<.08\right)$.

There was a localized negativity over the midline frontal-central region of the scalp around $400 \mathrm{msec}$ after cue onset that distinguished effector and attention + effector switches from repetitions (Figures 3 and 4A). The distribution of the frontal-central negativity was similar in the scalp voltage and surface Laplacian maps. This finding may indicate that this modulation of the ERPs arises from the activity of a neural generator located in the medial prefrontal cortex or supplementary motor area. The effect of type of switch on the frontal-central negativity was examined in a 4 (type of switch) $\times 2$ (dimension) $\times 2$ (response hand) ANOVA that included mean amplitude between 400 and $500 \mathrm{msec}$ after cue onset at electrode FCz. In this analysis, the main effect of type of switch was significant $\left[F(3,75)=12.86, p<.001, \eta_{\mathrm{p}}^{2}=.34\right.$, 

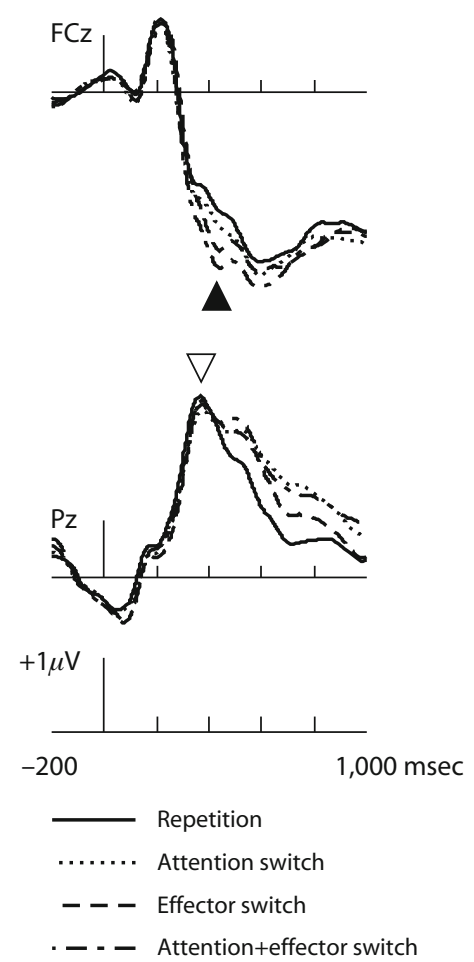

Figure 3. Grand-averaged ERPs at electrodes $\mathrm{FCz}$ and Pz. The frontal-central negativity (filled arrow) related to effector switching can be seen at electrode $\mathrm{FCz}$ and the P3b (open arrow) at electrode Pz. The tall bar represents cue onset and the short bars represent 200-msec increments.

$\varepsilon=.96]$. Voltage was more negative for effector switches $(M=-2.77 \mu \mathrm{V})$ and attention + effector switches $(M=$ $-3.08 \mu \mathrm{V})$ than for repetitions $[M=-2.18 \mu \mathrm{V}, F(2,50)=$ 20.60, $\left.p<.001, \eta_{\mathrm{p}}^{2}=.45, \varepsilon=.93\right]$. The difference between attention switches $(M=-2.44 \mu \mathrm{V})$ and repetitions was not significant $\left[F(1,25)=2.86, p>.10, \eta_{\mathrm{p}}^{2}=.10\right]$. The time course and topography of the frontal-central negativity are consistent with that of the frontal positivity observed by Rushworth, Passingham, and Nobre (2002, 2005); however, the two modulations possess the opposite polarity, making it unlikely that they arise from the same neural generators.

Effector switching was associated with a readiness potential over the central region of the scalp that reflected greater negativity over the hemisphere contralateral to the response hand for effector switches and attention+effector switches, relative to repetitions and attention switches (Figures 4B and 5). This modulation emerged around $300 \mathrm{msec}$ after cue onset and persisted over the remainder of the analyzed epoch. For the left and right hemispheres, the surface Laplacian maps revealed a polarity reversal over the central region that probably reflects that activity of a current dipole in premotor cortex. The effect of type of switch on the readiness potential was examined in a 2 (response hand) $\times 2$ (region: left or right) $\times$ 2 (dimension) $\times 3$ (type of switch: repetitions, effector switch, attention + effector switch) $\times 3$ (electrode: FC3$\mathrm{FC} 4, \mathrm{C} 3-\mathrm{C} 4$, and $\mathrm{C} 5-\mathrm{C} 6$ ) ANOVA performed on mean
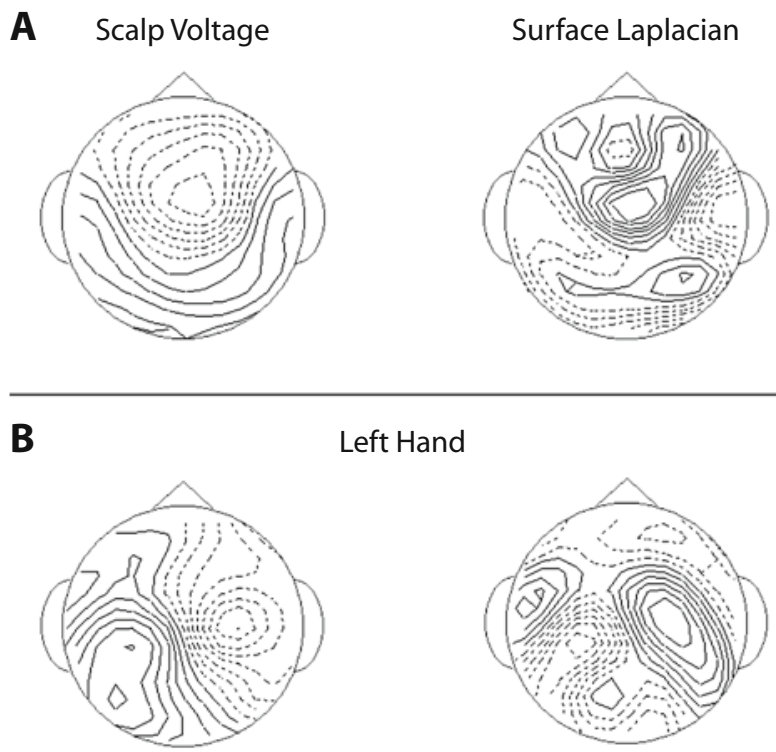

Left Hand

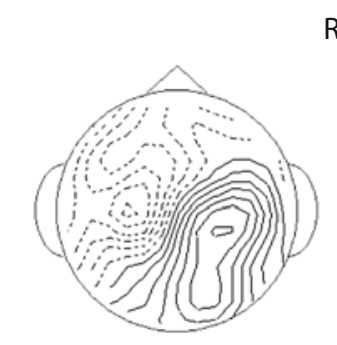

Right Hand

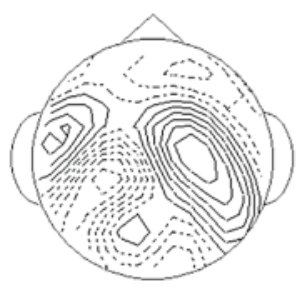

Right Hand
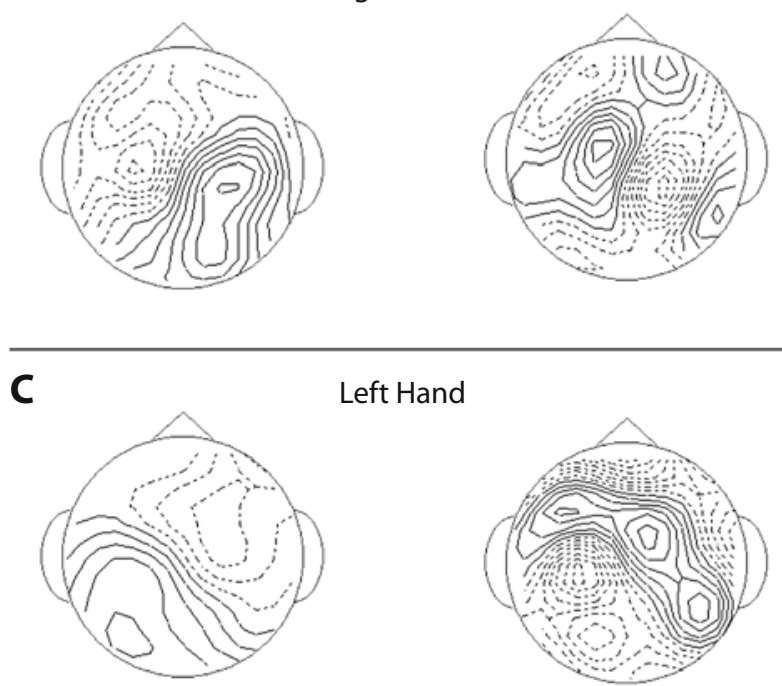

Left Hand

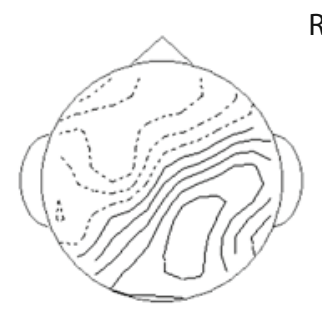

Right Hand
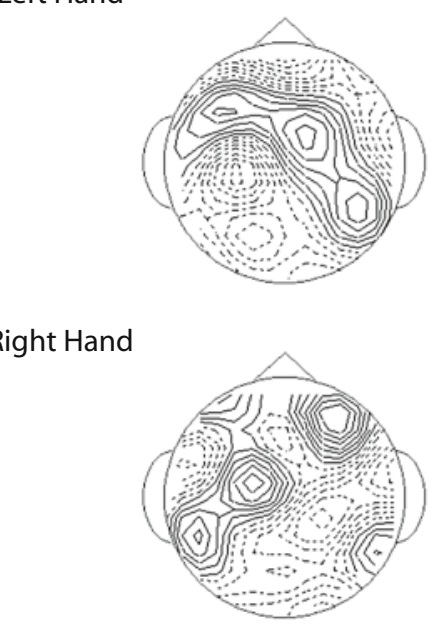

Figure 4. Isopotential maps for the scalp (left) and surface Laplacian (right) demonstrating the topography of the (A) frontal negativity (410 msec), representing the difference between effector switches and repetitions; (B) readiness potential $(500 \mathrm{msec})$, representing the difference between effector switches and repetitions; and (C) parietal slow wave $(650 \mathrm{msec})$, representing the difference between attention + effector switches and repetitions. Positive voltage is plotted as solid lines; negative voltage, as broken lines. The isobars for scalp voltage represent $0.15 \mu \mathrm{V}$ for the frontal-central negativity, $0.12 \mu \mathrm{V}$ for the readiness potential, and $0.30 \mu \mathrm{V}$ for the parietal slow wave; the surface Laplacian maps represent $0.94 \mu \mathrm{V}$ for the frontal-central negativity, $1.4 \mu \mathrm{V}$ for the readiness potential, and $1.4 \mu \mathrm{V}$ for the parietal slow wave. 
Left-Hand Responses
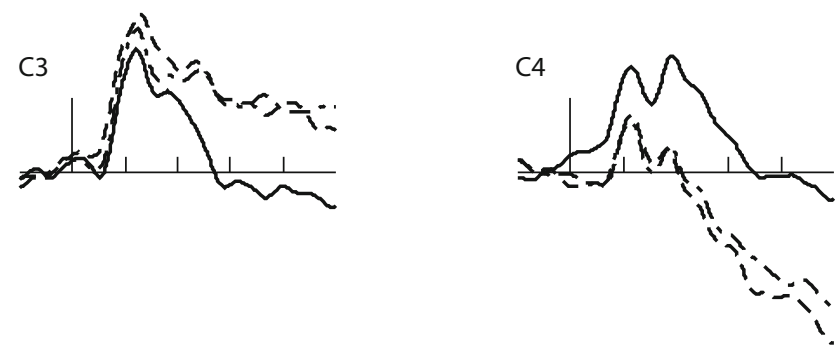

Right-Hand Responses
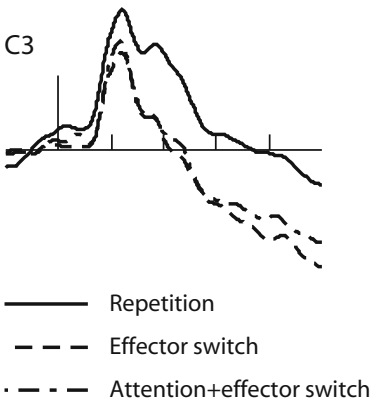
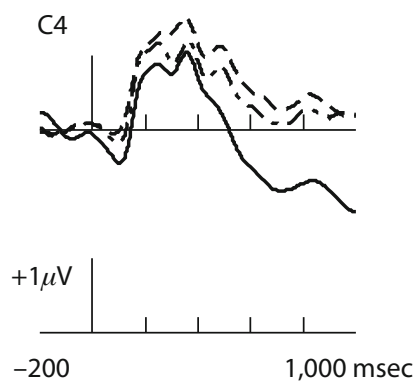

Figure 5. Grand-averaged ERPs at electrodes C3 and C4 demonstrating the time course of the readiness potential over the central region of the scalp. The tall bars represent cue onset and the short bars represent 200-msec increments.

voltage between 300 and $1,000 \mathrm{msec}$ after cue onset. In this analysis, the response hand $\times$ region $\times$ trial interaction was significant; see Figure $5[F(2,50)=77.94, p<$ $\left..001, \eta_{\mathrm{p}}^{2}=.76, \varepsilon=.93\right]$. The interaction resulted from the tendency for the effect of hemisphere to be stronger for the right hemisphere than for the left hemisphere, which may indicate that effector switching was more difficult when the nondominant hand was used. As would be expected on the basis of the data presented in Figure 5, a follow-up analysis, including data for effector switches and attention +effector switches, failed to reveal a significant effect of type of switch $[F(1,25)=1.07, p>$ $\left..30, \eta_{\mathrm{p}}^{2}=.04\right]$. These findings indicate that the processes represented by the readiness potential were insensitive to the additional demands of attention switching present for attention + effector switch trials.

As in previous studies (Jost et al., 2008; Kieffaber \& Hetrick, 2005; West \& Moore, 2005), attention switching was associated with a parietal slow wave that followed the P3b. Examination of the scalp voltage and surface Laplacian maps reveals that the parietal slow wave may reflect the activity of a localized dipole in the parietal cortex that varies in location with the response hand. The scalp voltage and surface Laplacian maps also reveal that for the right-hand responses the parietal slow wave was primarily related to attention switching (Figures 6 and 7), and that for the left-hand responses the parietal slow wave may be related to both attention and effector switching. For the left-hand responses, the parietal slow wave was more strongly expressed over the left parietal region for attention, effector, and attention + effector switches (Figures 4C, 6, and 7). In contrast, for the right- hand responses, the parietal slow wave was more strongly expressed over the right parietal region for attention and attention+effector switches.

The effects of task switching on the parietal slow wave were examined in a 2 (response hand) $\times 2$ (dimension) $\times$ 4 (type of switch) $\times 3$ (electrode: P3, Pz, and P4) ANOVA. The response hand $\times$ type of switch $\times$ electrode interaction was significant $\left[F(6,150)=15.03, p<.001, \eta_{\mathrm{p}}^{2}=\right.$ $.38, \varepsilon=.65]$. For the left hand, there was little difference between the type of switches at electrode $\mathrm{P} 4[F(3,75)=$ $\left.1.61, p>.20, \eta_{\mathrm{p}}^{2}=.06, \varepsilon=1.00\right]$; see Figure 7. In contrast, for the right hand, amplitude tended to be greater for effector switches $[M=0.62 \mu \mathrm{V}, F(1,25)=9.34, p<.001$, $\left.\eta_{\mathrm{p}}^{2}=.27\right]$ and attention + effector switches $[M=0.81 \mu \mathrm{V}$, $\left.F(1,25)=16.43, p<.001, \eta_{\mathrm{p}}^{2}=.40\right]$ than for repetitions $(M=-0.07 \mu \mathrm{V})$ at electrode $\mathrm{P} 4$. These findings may indicate that the right parietal region was recruited during task switching when responses were made with the right hand. For the left hand, there was a tendency for all three types of switch trials (attention, $M=1.51 \mu \mathrm{V}$; effector, $M=$ $1.81 \mu \mathrm{V}$; attention + effector, $M=2.14 \mu \mathrm{V})$ to elicit greater positivity than did repetitions $(M=0.84 \mu \mathrm{V})$ at electrode P3 $\left[F(3,75)=12.12, p<.001, \eta_{\mathrm{p}}^{2}=.33, \varepsilon=.96\right]$. For the right hand, in contrast, amplitude tended to be greater for attention switches $[M=2.07 \mu \mathrm{V}, F(1,25)=15.73, p<$ $\left..001, \eta_{\mathrm{p}}^{2}=.38\right]$, and possibly attention + effector switches $\left[M=1.41 \mu \mathrm{V}, F(1,25)=3.64, p<.07, \eta_{\mathrm{p}}^{2}=.12\right]$, than for repetitions $(M=0.99 \mu \mathrm{V})$ or effector switches $(M=$ $0.81 \mu \mathrm{V})$. Together, these data demonstrate that the parietal slow wave was sensitive to processes generally involved in task switching that contribute to both effector and attention switches. 

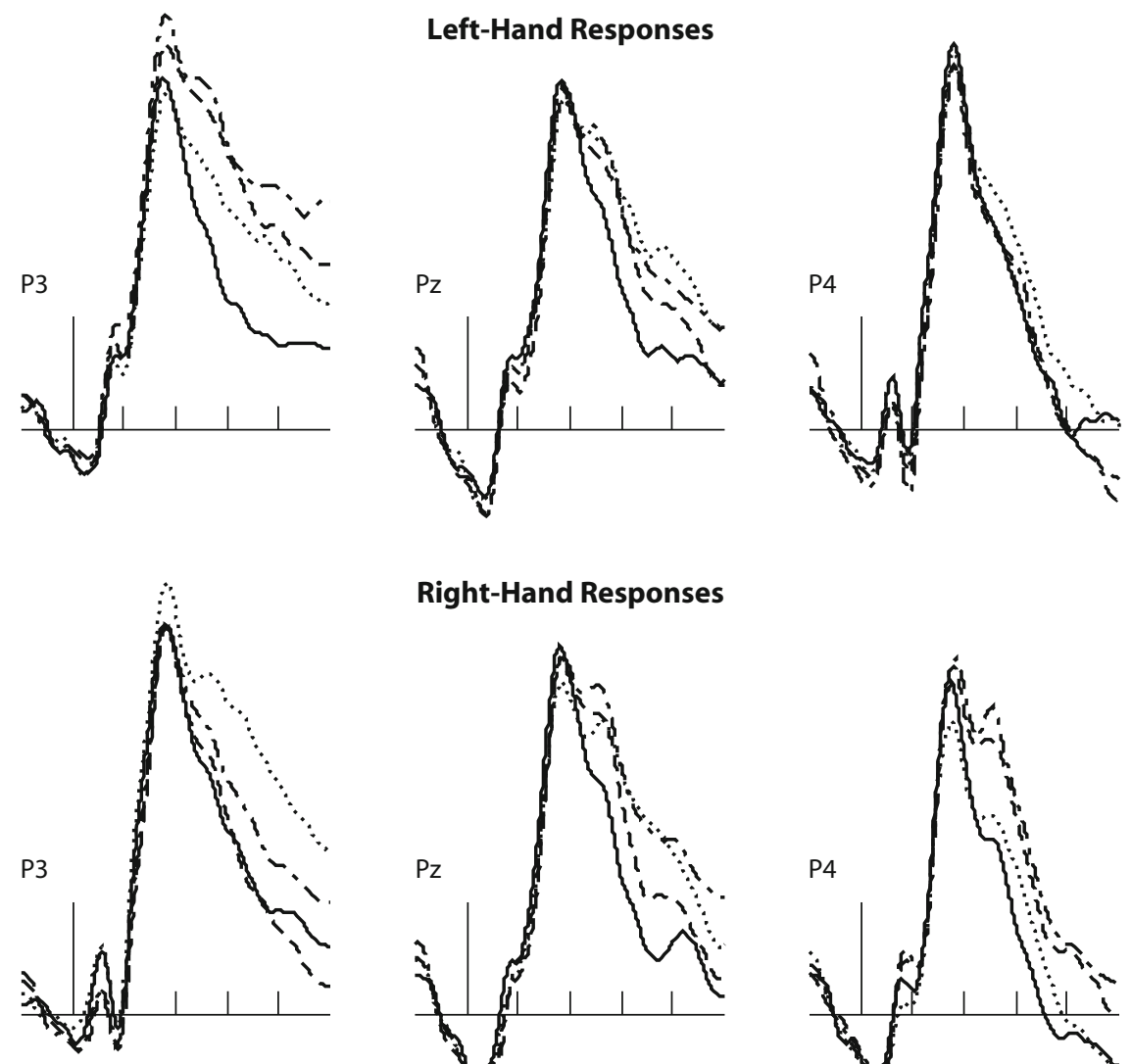

Right-Hand Responses
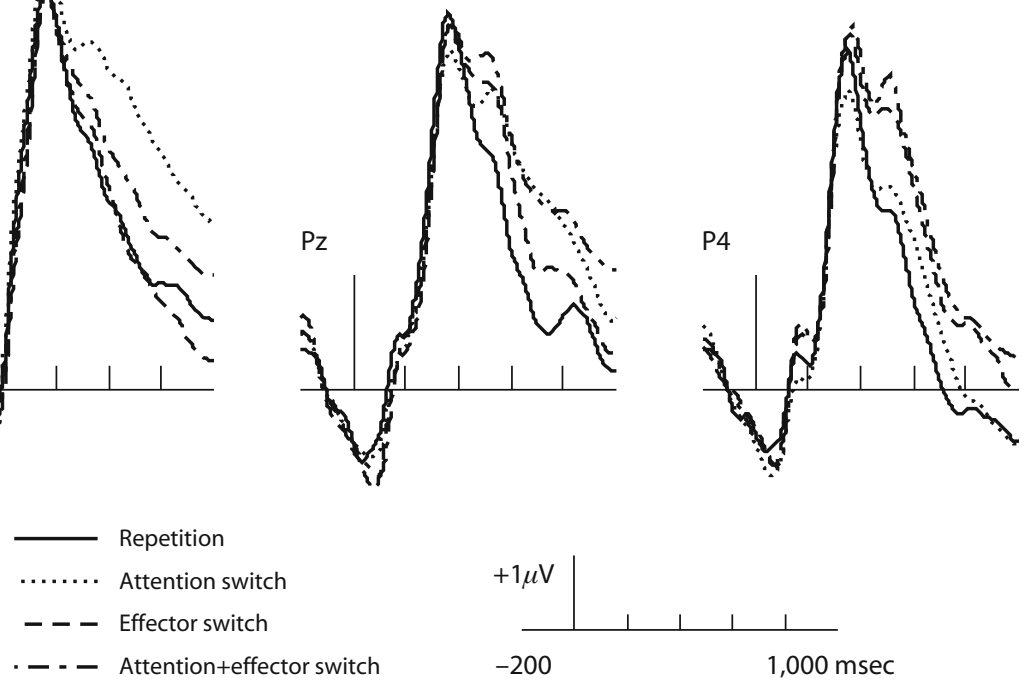

Figure 6. Grand-averaged ERPs at electrodes P3, Pz, and P4 demonstrating the time course of the parietal slow wave over the parietal region of the scalp. The tall bars represent cue onset and the short bars represent 200 -msec increments.

Left-Hand Responses

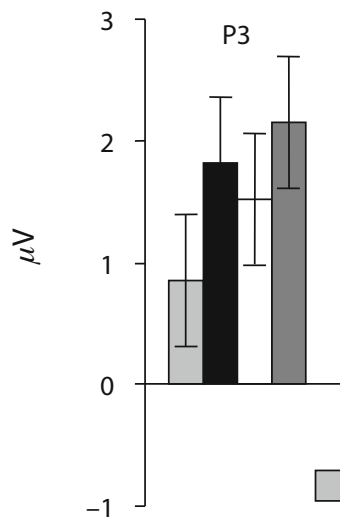

$\mathrm{Pz}$

P4

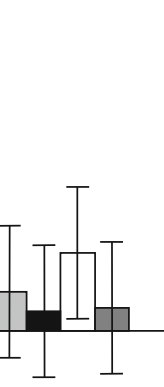

Repetition

Effector $\square$ Attention

Attention

Right-Hand Responses

P3

Pz

P4

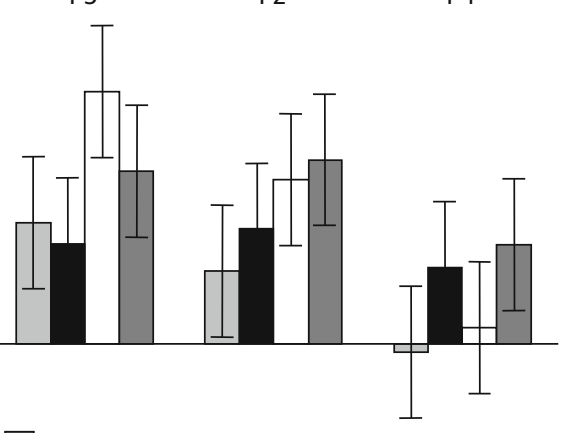

Attention+effector

Figure 7. Mean voltage for repetitions, effector switches, attention switches, and attention +effector switches at electrodes $\mathrm{P3}, \mathrm{Pz}$, and $\mathrm{P} 4$ demonstrating the type of switch $\times$ response hand $\times$ electrode interaction. The error bars represent the $95 \%$ confidence interval based on the error term for the three-way interaction. 


\section{Color Task}
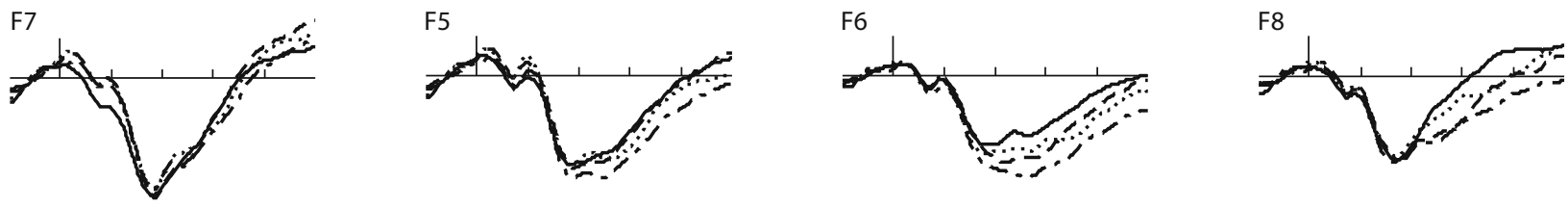

\section{Word Task}
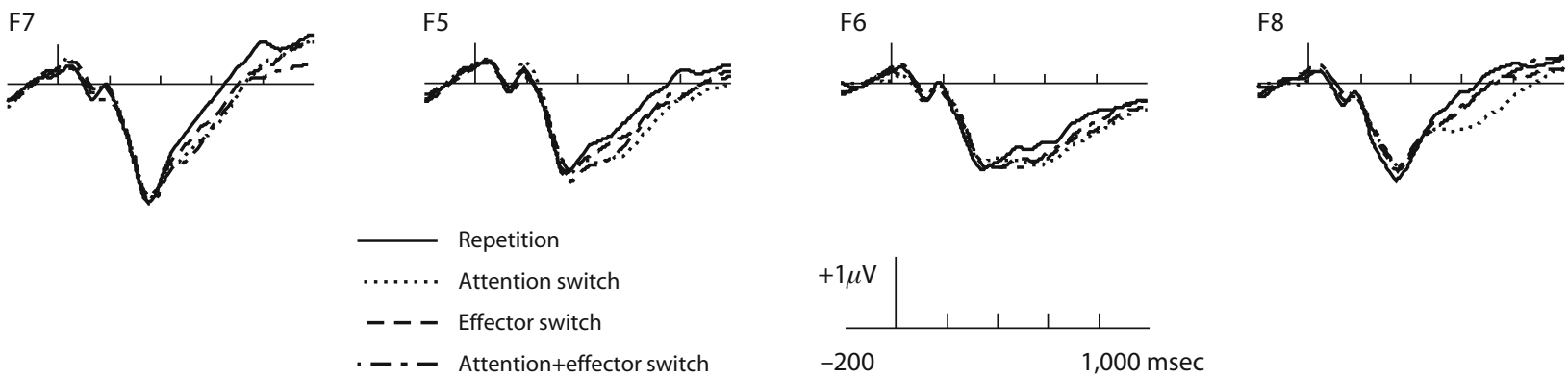

Figure 8. Grand-averaged ERPs at electrodes F7, F5, F6, and F8 demonstrating the time course of the frontal slow wave for the color and word identification tasks. The tall bars represent cue onset and the short bars represent 200 -msec increments.

The parietal slow wave was accompanied by a sustained modulation of the ERPs over the frontal region of the scalp, beginning around $400 \mathrm{msec}$ after stimulus onset, that reflected greater negativity for switch trials than for repetitions (Figure 8). Examination of the scalp voltage and surface Laplacian maps reveals a complex pattern over the frontal region of the scalp (Figure 4C), indicating that the frontal slow wave may reflect the activity of neural generators in medial and lateral prefrontal cortex. The effects of task switching on the frontal slow wave were examined in a 2 (response hand) $\times 2$ (dimension) $\times 4$ (type of switch) $\times 4$ (electrode: F7, F5, F6, F8) ANOVA. This analysis revealed a significant main effect of type of $\operatorname{switch}\left[F(3,75)=4.49, p<.01, \eta_{\mathrm{p}}^{2}=.15, \varepsilon=1.00\right]$. The main effect of type of switch was qualified by a dimension $\times$ type of switch interaction; see Figure $9[F(3,75)=$

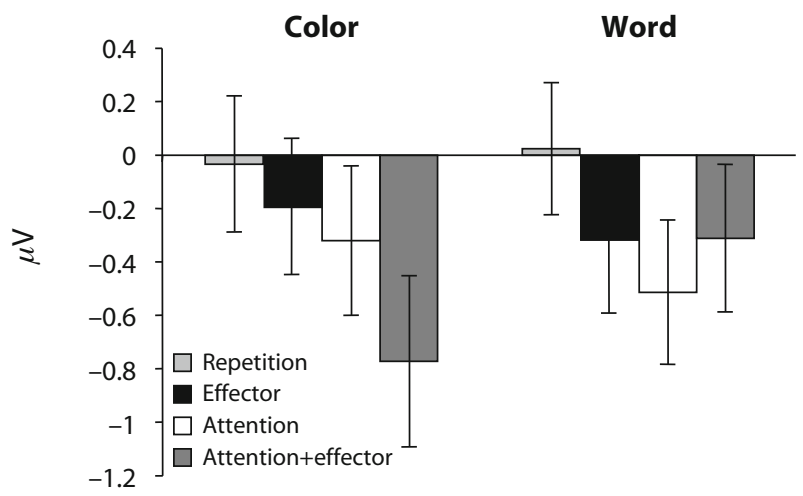

Figure 9. Mean voltage for repetitions, effector switches, attention switches, and attention+effector switches for the color and word identification tasks that demonstrates the dimension $\times$ type of switch interaction. The error bars represent the standard errors of the means. $\left.2.75, p<.05, \eta_{\mathrm{p}}^{2}=.10, \varepsilon=1.00\right]$. To characterize this interaction, separate analyses were performed for the color and word identification tasks. For the word identification task, there was a main effect of type of switch $[F(3,75)=$ $\left.3.86, p<.05, \eta_{\mathrm{p}}^{2}=.10, \varepsilon=1.00\right]$, and differences in amplitude between the three switch trials were not significant $(F<1.00)$. Together, these findings may indicate that for the word identification task, the effect of task switching on the frontal slow wave was similar for the three types of switches. For the color identification task, there was also a main effect of type of switch $[F(3,75)=4.54, p<$ $\left..01, \eta_{\mathrm{p}}^{2}=.15, \varepsilon=.98\right]$. Additionally, there was a significant difference in amplitude between the three types of switch trials $\left[F(2,50)=3.92, p<.03, \eta_{\mathrm{p}}^{2}=.14, \varepsilon=\right.$ $1.00]$ that appeared to result from greater negativity for attention + effector switches than for attention switches or effector switches (Figure 9). To quantify this difference, we performed an analysis in which mean voltage for attention+effector switches was compared with the average of the mean voltage for attention switches and effector switches. In this analysis, voltage was more negative for attention + effector switches $(M=-0.77 \mu \mathrm{V})$ than for the combined conditions $[M=-0.26 \mu \mathrm{V}, F(1,25)=8.88$, $\left.p<.01, \eta_{\mathrm{p}}^{2}=.26\right]$. This effect may indicate that greater frontal recruitment was required for the dual switch when individuals were switching from the more dominant task to the less dominant task.

\section{DISCUSSION}

The present study was designed to examine the neural correlates of attention and effector switching, and to determine how and when these two forms of task switching might interact. The RT data indicated that attention and effector switch costs were additive when responses were made with the right hand and were perhaps interac- 
tive when responses were made with the left hand. The ERP data revealed that effector switching was associated with a phasic negativity over the frontal-central region of the scalp, a sustained readiness potential over the central region of the scalp, and slow wave activity over the parietal and frontal regions of the scalp. The ERP data also revealed that attention switching was associated with both a parietal slow wave commonly observed in ERP studies of task switching (Kieffaber \& Hetrick, 2005; Nicholson et al., 2006; West \& Moore, 2005), and sustained activity over the frontal region of the scalp that has been less consistently reported in previous studies of task switching using ERPs. This finding is, however, in agreement with evidence from studies using fMRI that have consistently revealed activation of prefrontal cortex in response to task switching (Braver et al., 2003; Dove et al., 2000).

The behavioral data revealed robust switch costs for both attention and effector switching. In the response accuracy data, the switch costs were similar for attention and effector switching, and the switch costs for attention+effector switches were greater than when a single switch was performed. In the RT data, the magnitude of the switch costs tended to increase from attention switching to effector switching to attention + effector switching. The difference between attention switching and effector switching represents the opposite of what has been observed in some previous research, where switch costs were greater for attention than for effector switching (Kleinsorge \& Heuer, 1999; Tieges et al., 2007). It is not clear why our pattern of switch costs differs from that observed in previous studies. Tieges et al. used a within hand switch for the effector switch while we used a between hand switch for the effector switch. However, Kleinsorge and Heuer also used a between hand switch for their effector switch, so this does not seem to be the critical variable.

The nature of the relationship between attention switching and effector switching depended on the task to be performed and the response hand. Consistent with some prior research (Tieges et al., 2007), when the data were collapsed across response hand and stimulus dimension, attention and effector switch costs were generally additive (i.e., attention switch costs + effector switch costs $=$ attention + effector switch costs). This pattern was also observed for right-hand responses; in contrast, a different pattern was observed for left-hand responses. Specifically, there was a tendency for attention + effector switch costs to be superadditive for the word identification task, and to be subadditive for the color identification task. The difference in switch costs between the response hands was unexpected. However, an examination of response dominance (i.e., the difference in RT between color and word identification) across the various task conditions may reveal the locus of this effect. For all conditions other than the left-hand attention+effector switches, the typical pattern of response dominance was observed (i.e., word identification was faster than color identification). In contrast, for the left-hand attention+effector switches response dominance was reversed (i.e., RT was $33 \mathrm{msec}$ slower for word identification trials than for color identification trials). Given this finding, it may be that competition arises when the right hemisphere (likely the nondominant hemisphere in this sample of individuals) must simultaneously configure the attention and effector task set in order to implement the word identification task.

Effector switching was associated with a frontal-central negativity around $400 \mathrm{msec}$ after cue onset. The topography of the frontal-central negativity was similar in the scalp voltage and surface Laplacian maps. This finding leads to the suggestion that the frontal-central negativity arises from the activity of neural generators in superficial medial frontal cortex (e.g., supplementary motor area), rather than anterior cingulate cortex. This suggestion is based on the observation that deep sources tend not to contribute to activity observed in surface Laplacian maps (Nunez \& Srinivasan, 2006). The association of the frontal-central negativity with activity in the supplementary motor area is consistent with evidence from a number of studies using fMRI to examine the functional neuroanatomy of task switching that have revealed activation in this region (Braver et al., 2003; Dove et al., 2000; Smith et al., 2004). Because of the novelty of the frontalcentral negativity, it is difficult to determine what specific cognitive process(es) are reflected by this modulation of the ERPs. As the frontal-central negativity appeared to be limited to effector switches, it would not seem to reflect processes generally related to task switching, such as cue retrieval or task set configuration, that contribute to the parietal slow wave and were observed for all three types of switches. Given the limited number of studies that have examined the ERP correlates of effector switching, it seems that additional research is required to identify the conditions under which the frontal-central negativity is elicited and thereby gain a better understanding of the processes supporting effector switching.

Effector switching was also associated with a readiness potential that reflected greater negativity over the central region of the scalp contralateral to the response hand. In the scalp voltage maps, the readiness potential reflected activity extending from the central to parietal or central to frontal regions of the scalp, depending on which side of the dipole was under consideration. In the surface Laplacian maps, the readiness potential reflected a focused polarity inversion over the central region, probably arising from a dipole in premotor cortex. Additionally, for the left-hand responses, the central dipole reflecting the readiness potential was accompanied by a negativity in the surface Laplacian map over the left parietal region similar to that associated with attention switching. These findings may indicate that effector switching primarily involves the recruitment of structures within premotor areas when the dominant hand is used for the response, and that the additional recruitment of structures within parietal cortex becomes necessary when the nondominant hand is used for the response. The presence of the parietal slow wave for effector switches involving the left hand is interesting within the context of the finding that this modulation of the ERPs is also typically greater in amplitude for the color task than for the word task when Stroop stimuli are incorporated in the paradigm (Travers \& West, 2008; West \& Moore, 2005). Together these findings may 
indicate that processes underlying task set configuration are particularly important when individuals switch from a dominant to a nondominant response set, regardless of whether this involves an attention or effector switch.

Consistent with previous research, attention switching was associated with the parietal slow wave beginning around $500 \mathrm{msec}$ after cue onset (Jost et al., 2008; Kieffaber \& Hetrick, 2005; Nicholson et al., 2006). This finding converges with evidence from studies using fMRI, where task switching is consistently associated with activation of superior and inferior parietal cortex (Braver et al., 2003; Dove et al., 2000). The parietal slow wave was accompanied by slow wave activity over the frontal region of the scalp, beginning around $400 \mathrm{msec}$ after cue onset, that also distinguished switch trials from repetitions. Additionally, for the color, but not word, identification task the amplitude of the frontal slow wave was greater for dual switches than for attention or effector switches. This finding may indicate that dual switches place particularly heavy demands on processes supporting task set configuration when the transition is from the dominant to the nondominant task set. Frontal recruitment could be anticipated, judging from work using fMRI, but it has been less consistently observed in prior work using ERPs to examine the neural correlates of task switching. In the scalp voltage maps the parietal slow wave appeared to be more strongly expressed over the left hemisphere, particularly for righthand responses. In the surface Laplacian maps the parietal slow wave appeared to be more strongly expressed over the left hemisphere for left-hand responses and to shift to the right hemisphere for right-hand responses. The hemispheric shift in the parietal slow wave represents an interesting yet unexpected finding that warrants further investigation. It is possible that this hemispheric shift may have been obscured in previous research that relied on righthand responses or collapsed across left- and right-hand responses. These findings indicate that neural generators in both frontal and parietal cortex may contribute to task set configuration in the current paradigm.

An interesting finding of the present study was the effect of response hand on the relationship between attention and effector switching. For the right-hand responses, attention and effector switch costs were additive in the RT data for the attention+effector trials. For the ERP data, attention switching was primarily associated with sustained activity over the parietal and frontal regions of the scalp, and effector switching was primarily associated with the frontalcentral negativity and the readiness potential. In contrast, for the left-hand responses, attention and effector switch costs interacted, being subadditive when color identification was required and superadditive when word identification was required. An interaction between attention and effector switching was also observed in the ERP data, in which the parietal slow wave was observed for both attention and effector switching when the left hand was used for the response. Furthermore, data from the attention+effector switch trials may indicate competition for the recruitment of processes underlying task set configuration supported by parietal and frontal cortex, when attention and effector switches are implemented on the same trial. The generaliz- ability of the differences between the left and right hemispheres in implementing task switching is difficult to ascertain on the basis of previous research that has tended to collapse across responses made with the left and right hands (Kieffaber \& Hetrick, 2005; Tieges et al., 2007). Given this, one fruitful avenue of future research might be to explore the boundary conditions under which different types of task switches may lead to differential recruitment of structures within left and right parietal cortex.

In conclusion, the present study revealed distinct modulations of the ERPs differentially related to effector switching and attention switching. For right-hand responses, switch costs for RT were additive for attention and effector switches, attention switching was primarily associated with the parietal slow wave, and effector switching was primarily associated with the readiness potential. In contrast, for the left-hand responses, switch costs for RT were nonadditive and interacted with the task to be performed. Attention switching was associated with the parietal slow wave, and effector switching was associated with both the readiness potential and the parietal slow wave. Together, these findings may indicate that the independence of the neural systems supporting attention and effector switching was only revealed when the dominant hemisphere controlled the response.

\section{AUTHOR NOTE}

Correspondence concerning this article should be addressed to R. West, Department of Psychology, Iowa State University, W1112 Lagomarcino Hall, Ames, IA 50011 (e-mail: rwest@iastate.edu).

\section{REFERENCES}

Allport, D. A., Styles, E. A., \& Hsieh, S. (1994). Shifting intentional set: Exploring the dynamic control of tasks. In C. Umiltà \& M. Moscovitch (Eds.), Attention and performance $X V$ : Conscious and nonconscious information processing (pp. 421-452). Cambridge, MA: MIT Press.

Altmann, E. M. (2004). Advance preparation in task switching: What work is being done? Psychological Science, 15, 616-622. doi:10.1111/j.0956-7976.2004.00729.x

Aron, A. R., Watkins, L., Sahakian, B. J., Monsell, S., Barker, R. A., \& Robbins, T. W. (2003). Task-set switching deficits in early-stage Huntington's disease: Implications for basal ganglia function. Journal of Cognitive Neuroscience, 15, 629-642. doi:10.1162/089892903322307357

Braver, T. S., Reynolds, J. R., \& Donaldson, D. I. (2003). Neural mechanisms of transient and sustained cognitive control during task switching. Neuron, 39, 713-726. doi:10.1016/S0896 $-6273(03) 00466-5$

Coles, M. G. H., Smid, H. G. O. M., Scheffers, M. K., \& Otten, L. J. (1995). Mental chronometry and the study of human information processing. In M. D. Rugg \& M. G. H. Coles (Eds.), Electrophysiology of mind: Event-related brain potentials and cognition (pp. 86-131). New York: Oxford University Press.

Dove, A., Pollmann, S., Schubert, T., Wiggins, C. J., \& von CraMON, D. Y. (2000). Prefrontal cortex activation in task switching: An event-related fMRI study. Cognitive Brain Research, 9, 103-109. doi:10.1016/S0926-6410(99)00029-4

Eppinger, B., Kray, J., Mecklinger, A., \& John, O. (2007). Age differences in task switching and response monitoring: Evidence from ERPs. Biological Psychology, 75, 52-67. doi:10.1016/j .biopsycho.2006.12.001

HuYNH, H., \& FELDT, L. S. (1976). Estimation of the Box correction for degrees of freedom from sample data in randomized block and splitplot designs. Journal of Educational \& Behavioral Statistics, 1, 69-82. doi:10.3102/10769986001001069

Jost, K., MAYr, U., \& RösLer, F. (2008). Is task switching nothing but 
cue priming? Evidence from ERPs. Cognitive, Affective, \& Behavioral Neuroscience, 8, 74-84. doi:10.3758/CABN.8.1.74

Kieffaber, P. D., \& Hetrick, W. P. (2005). Event-related potential correlates of task switching and switch costs. Psychophysiology, 42, 5671. doi:10.1111/j.1469-8986.2005.00262.x

Kleinsorge, T., \& Heuer, H. (1999). Hierarchical switching in a multi-dimensional task space. Psychological Research, 62, 300-312. doi: $10.1007 / \mathrm{s} 004260050060$

Kray, J., Eppinger, B., \& Mecklinger, A. (2005). Age differences in attentional control: An event-related potential approach. Psychophysiology, 42, 407-416. doi:10.1111/j.1469-8986.2005.00298.x

LogAN, G. D. (2003). Executive control of thought and action: In search of the wild homunculus. Current Directions in Psychological Science, 12, 45-48. doi:10.1111/1467-8721.01223

Logan, G. D., \& Bundesen, C. (2003). Clever homunculus: Is there an endogenous act of control in the explicit task-cuing procedure? Journal of Experimental Psychology: Human Perception \& Performance, 29, 575-599. doi:10.1037/0096-1523.29.3.575

Mayr, U., Diedrichsen, J., Ivry, R., \& Keele, S. W. (2006). Dissociating task-set selection from task-set inhibition in the prefrontal cortex. Journal of Cognitive Neuroscience, 18, 14-21. doi:10.1162/089892906775250085

MaYR, U., \& Kliegl, R. (2003). Differential effects of cue changes and task changes on task-set selection costs. Journal of Experimental Psychology: Learning, Memory, \& Cognition, 29, 362-372. doi:10.1037/0278-7393.29.3.362

Miller, E. K., \& Cohen, J. D. (2001). An integrative theory of prefrontal cortex function. Annual Review of Neuroscience, 24, 167-202. doi:10.1146/annurev.neuro.24.1.167

Monsell, S. (2003). Task switching. Trends in Cognitive Sciences, 7, 134-140. doi:10.1016/S1364-6613(03)00028-7

Monsell, S., \& Mizon, G. A. (2006). Can the task-cuing paradigm measure an endogenous task-set reconfiguration process? Journal of Experimental Psychology: Human Perception \& Performance, 32, 493-516. doi:10.1037/0096-1523.32.3.493

Nicholson, R., Karayanidis, F., Bumak, E., Рoboka, D., \& Michie, P. T. (2006). ERPs dissociate the effects of switching task sets and task cues. Brain Research, 1095, 107-123. doi:10.1016/j .brainres.2006.04.016

NunEZ, P. L., \& SRINIVASAN, R. (2006). Electric fields of the brain: The neurophysics of EEG (2nd ed.). New York: Oxford University Press.

OLDFIELD, R. C. (1971). The assessment and analysis of handedness: The Edinburgh inventory. Neuropsychologia, 9, 97-113. doi:10.1016/0028 -3932(71)90067-4

Picton, T. W., Bentin, S., Berg, P., Donchin, E., Hillyard, S. A., JoHnson, R., ET AL. (2000). Guidelines for using human eventrelated potentials to study cognition: Recording standards and publication criteria. Psychophysiology, 37, 127-152. doi:10.1111/1469 $-8986.3720127$

Poulsen, C., Luu, P., Davey, C., \& Tucker, D. M. (2005). Dynamics of task sets: Evidence from dense-array event-related potentials. Cognitive Brain Research, 24, 133-154. doi:10.1016/j.cogbrainres.2005.01.008

Ravizza, S. M., \& Ciranni, M. A. (2002). Contributions of the prefrontal cortex and basal ganglia to set shifting. Journal of Cognitive Neuroscience, 14, 472-483. doi:10.1162/089892902317361985

Rogers, R. D., \& Monsell, S. (1995). Costs of a predictable switch between simple cognitive tasks. Journal of Experimental Psychology: General, 124, 207-231. doi:10.1037/0096-3445.124.2.207
Rushworth, M. F. S., Hadland, K. A., Paus, T., \& Sipila, P. K. (2002). Role of the human medial frontal cortex in task switching: A combined fMRI and TMS study. Journal of Neurophysiology, 87, 2577-2592. doi:10.1152/jn.00812.2001

Rushworth, M. F. S., Passingham, R. E., \& Nobre, A. C. (2002). Components of switching intentional set. Journal of Cognitive Neuroscience, 14, 1139-1150. doi:10.1162/089892902760807159

Rushworth, M. F., Passingham, R. E., \& Nobre, A. C. (2005). Components of attentional set-switching. Experimental Psychology, 52, 83-98. doi:10.1027/1618-3169.52.2.83

Smith, A. B., Taylor, E., Brammer, M., \& Rubia, K. (2004). Neural correlates of switching set as measured in fast, event-related functional magnetic resonance imaging. Human Brain Mapping, 21, $247-$ 256. doi: $10.1002 / \mathrm{hbm} .20007$

SRINIVASAN, R. (2005). High-resolution EEG: Theory and practice. In T. C. Handy (Ed.), Event-related potentials: A methods handbook (pp. 167-188). Cambridge, MA: MIT Press.

STROop, J. R. (1935). Studies of interference in serial verbal reactions. Journal of Experimental Psychology, 18, 643-662. doi:10.1037/ h0054651

Tieges, Z., Snel, J., KoK, A., Plat, N., \& Ridderinkhof, R. (2007). Effects of caffeine on anticipatory control processes: Evidence from a cued task-switch paradigm. Psychophysiology, 44, 561-578. doi:10.1111/j.1469-8986.2007.00534.x

Travers, S., \& West, R. (2008). Neural correlates of cue retrieval, task set configuration, and rule mapping in the explicit cue task switching paradigm. Psychophysiology, 45, 588-601. doi:10.1111/j.1469 -8986.2008.00658.x

Vanderhasselt, M.-A., De Raedt, R., Baeken, C., Leyman, L., \& D'HAENEN, H. (2006). The influence of rTMS over the right dorsolateral prefrontal cortex on intentional set switching. Experimental Brain Research, 172, 561-565. doi:10.1007/s00221-006-0540-5

WEST, R. (2004). The effects of aging on controlled attention and conflict processing in the Stroop task. Journal of Cognitive Neuroscience, 16, 103-113. doi:10.1162/089892904322755593

West, R., \& Moore, K. (2005). Adjustments of cognitive control in younger and older adults. Cortex, 41, 570-581. doi:10.1016/S0010 -9452(08)70197-7

West, R., \& Travers, S. (2008). Differential effects of aging on processes underlying task switching. Brain \& Cognition, 68, 67-80. doi:10.1016/j.bandc.2008.03.001

Woodward, T. S., Bub, D. N., \& Hunter, M. A. (2002). Task switching deficits associated with Parkinson's disease reflect depleted attentional resources. Neuropsychologia, 40, 1948-1955. doi:10.1016/ S0028-3932(02)00068-4

Yeung, N., Nystrom, L. E., Aronson, J. A., \& Cohen, J. D. (2006). Between-task competition and cognitive control in task switching. Journal of Neuroscience, 26, 1429-1438. doi:10.1523/ JNEUROSCI.3109-05.2006

\section{NOTE}

1. For this analysis, the data were collapsed across attention and effector switches.

(Manuscript received July 21, 2008; revision accepted for publication December 12, 2008.) 